Check for updates

The BMJ

Cite this as: $B M / 2021 ; 372: n 509$ http://dx.doi.org/10.1136/bmj.n509 Published: 19 February 2021

\title{
Covid-19: No evidence that vaccines can affect fertility, says new guidance
}

\section{Gareth lacobucci}

There is "absolutely no evidence" that covid-19 vaccines can affect the fertility of women or men, says new expert guidance.

The guidance, ${ }^{1}$ published by the Association of Reproductive and Clinical Scientists and the British Fertility Society, comes amid concerns that misinformation that has been circulating online about covid-19 vaccines and fertility may be putting some women off having the vaccine.

Kamlesh Khunti, professor of primary care diabetes and vascular medicine at the University of Leicester, told The BMJ that he was concerned that misinformation may have contributed to the lower uptake among doctors in a study he led of vaccination rates in hospital staff at Leicester hospital, which published preliminary findings ${ }^{2}$ this week.

"We've seen a lot of blatant misinformation that the vaccine may have an effect on fertility for younger women-that's coming through regularly on social media," he said.

The guidance refutes any link between the vaccines and fertility. "There is absolutely no evidence, and no theoretical reason, that any of the vaccines can affect the fertility of women or men," it says. People of reproductive age should get a covid-19 vaccine when they receive their invitation, including people who are trying to have a baby or thinking about having a baby in the future, the guidance says.

People undergoing fertility treatment (in vitro fertilisation (IVF), frozen embryo transfer, egg freezing, ovulation induction, intrauterine insemination, or using donated gametes) can be vaccinated during treatment, but may wish to consider the timing given the potential side effects in the few days after vaccination. "It may be sensible to separate the date of vaccination by a few days from some treatment procedures (for example, egg collection in IVF), so that any symptoms, such as fever, might be attributed correctly to the vaccine or the treatment procedure," says the guidance.

People may start their fertility treatment immediately after being vaccinated, unless they wish to have a second dose before pregnancy, it adds.

The guidance also states that those who are donating their eggs or sperm for the use of others can still have a covid-19 vaccine.

Women who are pregnant can still have the vaccine if they are in a risk category for covid-19, but should delay vaccination until after pregnancy if they are not in a risk category, the guidance advises. "There is no reason to believe that any of the covid-19 vaccines would be harmful, but their effects in pregnancy have not yet been fully investigated," it says. "The information that is known is reassuring. None of the vaccines contain live virus and so there is no risk that the pregnant woman or her baby could get covid-19 from the vaccine."

People who have had recurrent miscarriages and are now trying to get pregnant do not need to postpone having a covid-19 vaccine, as it will not affect the risk of having a miscarriage, the guidance adds.

Raj Mathur, chair of the British Fertility Society and clinical lead for reproductive medicine at Manchester University NHS Foundation Trust, said the guidance had been welcomed by the profession. "Our reason for putting it out was because a lot of us were being asked questions by our patients and we noted hesitancy or reluctance from the angle of fertility," he told The BMJ. "The misinformation got there before the correct information."

"Also, vaccination is the best way of reducing your risk of catching covid-19 in pregnancy, and if you get it in pregnancy, in some ways the outcome is worse."

Association of Reproductive and Clinical Scientists, British Fertility Society. Covid-19 vaccines and fertility. 2021. www.britishfertilitysociety.org.uk/wpcontent/uploads/2021/02/Covid19-Vaccines-FAQ-1_3.pdf.

2 lacobucci G. Covid:19: Ethnic minority health staff are less likely to take up vaccine, early data show. BM/2021:372:n460. doi: 10.1136/bmj.n460 pmid: 33593814

This article is made freely available for use in accordance with BMJ's website terms and conditions for the duration of the covid-19 pandemic or until otherwise determined by BMJ. You may use, download and print the article for any lawful, non-commercial purpose (including text and data mining) provided that all copyright notices and trade marks are retained. 